\title{
LEER EL PASADO ANDINO EN LOS TEXTOS COLONIALES
}

\author{
READ THE ANDEAN PAST IN COLONIAL TEXTS
}

\author{
Francisco Hernández Astete*
}

El presente artículo está destinado a explorar la posibilidad de escribir historia aceca de un pueblo sin escritura, como los incas, partiendo de algunas preguntas, muchas de las cuales son evidentemente retóricas: ¿Se puede hacer historia sin fuentes escritas? ¿Cómo escribir respecto de los incas desde la historia si carecemos de escritura, pues hasta ahora nadie puede leer ninguno de los soportes que aparentan serlo, y es necesario hacer este proceso únicamente con textos coloniales y con evidencias materiales?

Palabras claves: Incas, crónicas, historia, fuentes.

This article is intended to explore the possibility of writing a History about a culture without writing, as the incas. For these reason we discussed some questions, many of which are obviously rhetorical: can be history exist without written sources? How to write about the incas from the history if we lack of writing, because so far no one can read any stands which appear to be so, and is necessary to make this process only with colonial texts and material evidence?

Key words: Incas, Chronicles, History, Sources.

\section{Introducción: El inicio de la Historiografía americana y el sentido de la Historia}

Cuando en la década de 1530 los españoles llegaron a los Andes, empezó también -junto con muchos otros complejos y, en ocasiones, dolorosos procesos- aquel que se dedicó a escribir la historia andina e insertarla, a su modo, a la historia de Occidente. Este no fue un proceso inocente; en algunas ocasiones fue orquestado por la burocracia Habsburgo con claros matices políticos, que llegaron a su máxima expresión cuando Felipe II prohibió, por real cédula, la investigación relativa a la historia inca, luego de que se publicara aquella que Toledo, el virrey, mandara a escribir a Pedro Sarmiento de Gamboa. Es de estos textos de los que queremos hablar ahora, de las llamadas Crónicas de Indias, pues -como se señaló- la historia de los incas se viene escribiendo casi sistemáticamente desde el siglo XVI, cuando muchos de los primeros españoles que llegaron a los Andes se convirtieron en voluntarios seguidores de Clío y empezaron a plantear preguntas similares a las que hoy seguimos formulando al universo andino prehispánico. Curiosamente, luego de más de 450 años de historiografía incaica, estas y otras interrogantes continúan siendo dudas permanentes para aquellos que intentan internarse en el pasado más antiguo de la historia del Perú y América. Hoy, sin embargo, tenemos -paradójicamente- más recursos metodológicos para escudriñar en el pasado, pero muchísimas más limitaciones que aquellos que vieron en funcionamiento -aunque al final- al mítico y real Tahuantinsuyo, pues no queda ya ningún quipucamayoc que consultar ni ningún descendiente de los incas que entrevistar. Con todo eso, evidentemente, no podemos dejar de interrogar a los cronistas, aunque en los últimos años hayan sido acusados de mentirosos e indecentes plagiadores, y, más aún, acusados de analizar la sociedad incaica y andina precolonial a partir de sus propias categorías de interpretación. Es factible anotar que esta práctica, a todas luces, ha sido realizada y la seguimos realizando todos los que de una u otra forma nos dedicamos a la investigación histórica, pues es imposible que nos despojemos plenamente de los prejuicios culturales que nos son inherentes y es siempre desde alguna perspectiva que se produce el conocimiento.

Nos gustaría empezar este artículo -destinado a explorar la posibilidad de escribir historia acerca de un pueblo sin escritura, como los incas- partiendo de algunas preguntas, muchas de las cuales son evidentemente retóricas: ¿Se puede hacer historia sin fuentes escritas? ¿Cómo escribir respecto de los incas desde la historia si carecemos de escritura, pues hasta ahora nadie puede leer ninguno de los soportes que aparentan serlo, y es necesario hacer

\footnotetext{
* Pontificia Universidad Católica del Perú. Lima, Perú. Correo electrónico: fhernan@ pucp.edu.pe
} 
este proceso únicamente con textos coloniales y con evidencias materiales?

Vale la pena, entonces, ensayar una respuesta partiendo de ciertos axiomas que parecen acompañar al quehacer del historiador. En ese sentido, me gustaría plantear una idea previa, y es que el interés por la historia, si la entendemos como conservación de la memoria, es anterior al desarrollo de la disciplina. En cierto sentido, también es una suerte de tendencia innata humana. Así, desprovisto de todo conocimiento científico o-mejor-sin ningún entrenamiento en las disciplinas que pueden calificar como tales, un niño se pregunta y se interesa por su origen, pregunta a sus padres por los acontecimientos que marcaron su vida y necesita ubicarse en el mundo. La pregunta por el origen casi puede calificarse como innata, inherente al ser humano, como un acto natural. En esa línea, entiendo la historia como una condición natural al ser humano. Por eso, desde las pinturas rupestres hasta las expresiones más contemporáneas, podemos observar los grandes esfuerzos que hace el ser humano por trascender la finitud a la que lo condena el tiempo. Dejemos para otra ocasión una pregunta que es necesaria resolver, y es si la historia termina siendo una lucha o una reconciliación con la idea de finitud que atormenta al hombre desde hace mucho tiempo.

Sea cual fuese la respuesta a la pregunta anterior, individuos, colectividades, grupos y Estados invierten energía y recursos en la construcción de sus historias y, en una suerte de lucha por la memoria, pugnan por ofrecer una versión que se adecue mejor a sus necesidades de entendimiento del presente y de proyección futura.

Ahora bien, si aceptamos también que la historia estudia el pasado, es necesario responder a algunas preguntas de vital importancia: ¿Cuál es el pasado que estudia la Historia? ¿Se trata de todo el pasado, de absolutamente todo, o solo de lo importante? Si es solo lo importante, ¿cuál es el criterio universal para descartar algo? ¿Bajo qué pautas morales podemos decirle a un acontecimiento, a la vida de una persona, a una guerra o una forma de pensar "tú no eres importante; no pasarás a la historia"? Los historiadores, con nuestras preguntas y nuestros escritos, decidimos -y, para esto, no hay remedionuestros temas. En estas decisiones, hay miles de datos que quedan sin ser registrados o analizados, sin pasar a la historia. Esto es así, y es grave sobre todo si nos damos cuenta del afán, muchas veces compulsivo, del hombre por "pasar a la historia".
Parecería que las personas y sus acciones estuvieran permanentemente compitiendo para que no se les olvide jamás. Quizás, la Historia constituya una de las maneras en las que el hombre tiene de enfrentarse a su propia finitud. Basta ver los carteles que anuncian que una obra, por pequeña que sea, fue construida por alguien, o recordar a aquellos "mecenas" que dejan en el Primer Mundo, e incluso en el Tercero, sus fortunas a instituciones educativas y culturales con la condición de que le pongan su nombre a un edificio, un concurso o hasta a una banca. Esto se puede comprobar fácilmente si leemos los pequeños carteles que aparecen en cada una de las bancas del flamante auditorio del Museo de Arte de Lima (MALI). Citamos tres ejemplos: "AFP Integra", "Mamie y Roberto Abusada" y, finalmente, el siguiente: "A la mujer que marcó mi vida Ruth Estefanía Montoya y a nuestra hija Carissa Lukac. Con Amor Roberto". Es de rescatar que este último no ha sido obtenido al observar por la ventana uno de los miles de taxis que circulan por la ciudad de Lima, sino -como indiqué- de una de las bancas del auditorio del MALI.

Como se señaló previamente, la Historia constituye una de nuestras principales armas de lucha contra la muerte; por eso, previo a esta, hay una suerte de lucha por la Memoria. En este punto, las realidades históricas (acontecimientos, coyunturas, etc.) pugnan por integrar lo que llamamos "Historia". Respecto de ello, vale la pena preguntarnos qué es lo que puede integrar la historia si, de hecho, hay una selección por parte de quien la escribe. ¿Qué características tienen estas realidades en sí mismas para ser consideradas parte de la historia? Pongamos un ejemplo: es conocido por todos que el hecho de que se señale al 14 de julio como día nacional francés corresponde a un acuerdo, justificable pero arbitrario. Bien podrían haberse seleccionado el 21 de enero de 1793 (día del guillotinamiento de Luis XVI) o el 20 de junio de 1789 (día en el que los diputados juraron en el salón del juego de la pelota que no dejarían de reunirse hasta otorgarle a Francia una Constitución). Se podría pensar en los argumentos que se usaron para elegir una fecha y no otra, pero, en definitiva, los historiadores trabajan con un limitado número de realidades históricas con las que se puede ejercer la arbitrariedad de la disciplina.

Viene, entonces, la pregunta sobre si hay algo "ahistórico" en la historia, en estas realidades que permiten que sean o no candidatos a ser historiables. 
Evidentemente, la respuesta está en su capacidad para resignificar el pasado y preparar un futuro acorde con las necesidades del presente. No voy a recorrer ahora este camino, pero vale la pena anunciar que los historiadores trabajamos con un limitado y estrecho grupo de "acontecimientos" o "realidades históricas", cuyas características permiten que sean historiables y que, por razones de espacio, no vamos a profundizar en esta ocasión.

Intentamos, sí, empezar por reconocer que lo que podríamos llamar nuestro primer universal histórico; es decir, la primera de las características ahistóricas que permiten que una realidad pueda o no ser historiable es aquella que permite a esta realidad histórica responder satisfactoriamente -luego de una selección, construcción de un discurso y validación social- a lo que podemos llamar la pregunta por el origen o -quizás mejor- "la pregunta por el origen con sentido". Esta, por cierto, constituye una necesidad universal, individual y colectiva. Así, al margen de que se trate de un hecho fáctico, de un ritual, de una "leyenda", una performance o un mito, toda cultura tiene una respuesta para esta pregunta. Valdría la pena aquí explorar qué hace que un individuo reconozca en una respuesta la validez necesaria como para colmar sus ansias de saber acerca de él, su familia o sociedad. En resumen, ¿qué hace que una determinada respuesta pueda ser asimilada como propia y convertirse en un conocimiento histórico capaz de responder a las necesidades humanas de comprensión de la propia individualidad y colectividad?

Evidentemente en este proceso pasamos por dos etapas: la capacidad de reconocernos diferentes ante un otro, y la validez de las explicaciones de la propia existencia y de la importancia de la misma. De hecho, una de las preguntas esenciales de la historia es la pregunta por el origen, la construcción de un ser social que pueda articular nuestras individualidades dentro del complejo social. Por ello, colectivamente construimos una racionalidad histórica capaz de identificarnos como individuos insertados en determinadas colectividades y capaz de hacer de esas colectividades algo especial. Asumamos, entonces, dos preguntas: "¿Qué es lo que hace que una situación pueda ser calificada por todos como histórica?" y "¿Qué hace que la colectividad la acepte?". Dejemos, para volver en el futuro, el problema que tienen los Estados o de las colectividades para controlar la memoria individual y convencer al hombre de su realidad histórica, siempre a la sombra de un enemigo común; o la necesidad de sentirse grandes frente a otro inferior o salvaje. De hecho, en muchas culturas antiguas, la grandeza se construyó por la apología del propio héroe, por la satanización del enemigo común y por la autoidentificación como superior. En ese sentido, la tolerancia o la caridad davidsoniana es producto de una reflexión que tuvo que esperar hasta la centuria pasada para aparecer.

\section{Las crónicas coloniales y la historia incaica}

Empecemos ahora, luego de esta breve introducción, nuestra reflexión acerca de cómo, además de con las evidencias de la cultura material, ciertos textos escritos posteriormente nos pueden ayudar a comprender una realidad histórica anterior. Este es el caso de los cronistas y el estudio de la historia incaica.

De hecho, mucho de lo que recogieron los cronistas y transformaron en historias es lo que hoy podríamos considerar como las distintas respuestas que los pobladores andinos tuvieron frente a la pregunta por el origen. Así, aquellos que asumieron la tarea de escribir la historia de los Andes, desde el siglo XVI, empezaron a escuchar y a registrar los llamados mitos americanos, y los utilizaron como fuentes para la historia, en tanto estuvieron interesados en dar cuenta del pasado americano a sus lectores europeos. Es así como la tradición oral andina empezó a ser incorporada en la historiografía occidental.

\section{La oralidad escrita y la reconstrucción de la historia incaica}

Se debe señalar, sin embargo, que -como en toda utilización de la tradición oral como fuente para la Historia- hay que diferenciar entre los llamados testimonios (directos o indirectos) de las tradiciones orales, que pueden relacionarse con varios relatos de diversa índole (refranes, canciones, adivinanzas, cuentos, leyendas -narración de hechos memorables y mitos-, en tanto estén vinculados a explicaciones del mundo, de la religión o los orígenes de un pueblo). Desde el siglo XVI fueron utilizados los testimonios orales construidos por los investigadores -en este caso, cronistas o miembros de la burocracia española-, así como aquellos mitos y tradiciones que fueron recopilados en la búsqueda consciente que apuntaba a encontrar explicaciones 
que permitieran adentrarse en el pensamiento de la cultura que se intentaba conocer.

Como bien sabemos, los españoles llegaron a tierras americanas inmersos en una tradición textualista; para esto, no es relevante el hecho de que la mayoría de los recién llegados no supiera leer ni escribir. Aunque suene contradictorio, tenían instalada la forma de narrar, argumentar y referirse al mundo de una forma propia de la escritura. Los recién llegados consideraban, por ejemplo, que "la verdad" se encontraba revelada por escrito, de ahí el nombre de "Sagradas Escrituras". De hecho, es con un libro que se inicia la invasión de los Andes. Por esta razón, cuando escucharon las historias de los americanos, estas les parecieron "fábulas", en el sentido de falsas y opuestas a la Historia. Además, lo que los indígenas contaban y, sobre todo -como indica Manuel Gutiérrez Estévez (2001)- la manera en que lo hacían les resultaba caótica -por la "estructura argumental" de sus narraciones-, poco familiar y bastante opaca, debido a la pluralidad de versiones. No pudieron entender "la continuidad narrativa de unos personajes que, a lo largo de la trama, cambiaban de nombre, de características y de modo de comportarse" (Gutiérrez Estévez 2001:3). Así, acostumbrados a las versiones canónicas que ofrece la prosa escrita, la oralidad de la cultura americana les sorprendió, por decir lo menos. Sin embargo, y a favor de los primeros españoles que tomaron contacto con los originarios de América, debemos precisar que -por lo menos para el caso del Perú-, aunque con reparos, mostraron siempre interés por recoger estas "fábulas" y por difundirlas entre sus contemporáneos. Pese a ello, y como lamentablemente aún sucede, las características de la oralidad americana fueron confundidas con falta de competencia narrativa, debido a que les faltaba -y "les sigue faltando"- la disciplina de lo escrito, que es, a todas luces, entendida como superior. Así, uno de los más grandes conocedores de la cultura andina y de la lengua quechua, fray Cristóbal de Molina, manifestaba esta supuesta opacidad narrativa y se la atribuía a la falta de escritura:

Estos y otros desatinos semejantes decían y dicen haber pasado, que por prolijidad como dicho tengo, no los pongo. Causóse todo esto, demás de la principal causa que era no conocer a Dios y darse a vicios y idolatrías, no ser gentes que usaban de escritura, porque si la usaran, no tuvieran tan ciegos y torpes y desatinados errores y fábulas, no obstante que usaban de una cuenta muy sutil de unas hebras de lana de dos nudos, y puesta lana de colores en los nudos, los cuales llaman quipus (Molina 1989:57-58) $)^{1}$.

La información oral ha sido, de manera clásica, analizada por tradiciones textualistas y, como dice Zavala (2010), "leer" la oralidad a partir de los cánones de la prosa escrita no resulta una empresa muy acertada. Como es evidente, esto ha sido producto de la construcción de un discurso histórico desde una cultura dominante, que limita a lo escrito el valor de la verdad (Zavala 2010). En ese sentido, como una suerte de alternativa al análisis de la información oral -sobre todo, que comúnmente conocemos como la presente en los mitos, pues los testimonios merecen otro tratamiento-, la tradición oral está siendo entendida más como performance. Es decir, es entendida cada vez menos como un monólogo y más como una práctica, especie de narrativa conversacional. Se trata de una experiencia, un evento social del que se participa, por lo que el estudioso interesado en descubrir en ella las características de la cultura andina debe también prestar atención a la estructura de la participación y al contexto de la situación.

La comunicación oral no solo utiliza el sonido y el lenguaje, pues se nutre de otras expresiones asociadas también con la visión, el tacto y el movimiento. Las narraciones orales, como recuerda Zavala (2010), no tienen versiones canónicas. Tampoco es importante tener una, y no podemos afirmar-como se ha intentado muchas veces- que cierta versión de un mito es "más verdadera" que otra. Es simplemente otra, pero igual de válida. En opinión de Vich y Zavala, quienes recogen una larga tradición de lucha contra la literacidad como esquema dominante,

[...] la oralidad no solo es un texto; es un evento, una performance, y al estudiarla siempre debemos hacer referencia a un determinado tipo de interacción social. La oralidad es una práctica, una experiencia que se realiza y un evento del que se participa. Situada siempre en contextos sociales específicos, la oralidad produce un circuito comunicativo donde múltiples determinantes se disponen para 
constituirla. Es necesario afirmar que todos los discursos orales tienen significado, no solo por las imágenes que contienen, sino, además, por el modo en que se producen, por la circunstancia en la que se inscriben y por el público al que se dirigen (Vich y Zavala 2004:11).

Por ello, como recuerda Mannheim (1999), los mitos publicados son objetos ficticios, que responden a los cánones de la prosa escrita; y son, de hecho, distintos de los patrones orales de los que son extraídos. Asimismo, este autor menciona cómo, al finalizar el siglo pasado, en la década de 1980, en sus trabajos sobre el folklore tradicional de la Europa oriental, Jakobson afirmaba que la idea de que las narraciones tradicionales eran transmitidas de boca en boca a la siguiente generación constituía una fantasía propia de la proyección de la literatura escrita y de la filosofía social individualista (Mannheim 1999:48; Jakobson 1984 [1990]).

Resulta interesante recoger aquí la idea de Manuel Gutiérrez Estévez $(2001,2003)$ respecto de los mitos en general y, en particular, de los mitos amerindios. El autor señala claramente que los mitos no constituyen narraciones, sino que han sido transformados en tales mediante los cánones de la prosa escrita por dos operaciones: las preguntas del etnógrafo y su escritura posterior (Gutiérrez Estévez 2001, 2003). Para él, coincidiendo con lo que señalábamos anteriormente, el material que se denomina en general como "mitológico", y que puede ser transcrito e incluso estudiado como si se tratara de narraciones, surge de un cierto tipo de relación con los otros, pero no existe en la vida social.

Dentro de esta perspectiva, las narraciones sociales, entendidas como performances, son además colectivas y absolutamente participativas. Por eso, no hay distinción entre un "narrador" y su público oyente, debido a que la elaboración resulta de un proceso colectivo, en el que cada quien puede realizar una impugnación, comentario o añadido, que puede ser tomado de una suerte de repertorio, o almacén de escenas o figuras míticas, que cada uno de los miembros de las comunidades amerindias almacena en su memoria mediante los mecanismos propios de la transmisión del saber tradicional. Por esta razón, pretende referirse a las performances orales como una suerte de instalaciones de material mítico, que cobran sentido en la vida social y han sido despojadas de sus características de narraciones o textos míticos que le fueron asignadas por la tradición textualista que las analizó y utilizó durante mucho tiempo desde las ciencias sociales. Así, la materialización del "mito" ocurre por medio de unas reglas o instrucciones de uso que tácitamente todos conocen (Gutiérrez Estévez 2003).

Una de las más célebres frases que nos permiten entender el afán por textualizar la memoria oral nos es proporcionada por Claude Lévi-Strauss:

Sea cual fuere nuestra ignorancia de la lengua y la cultura de la población donde se lo ha recogido, un mito es percibido como mito por cualquier lector en el mundo entero (1968:190).

Llama la atención no solo el etnocentrismo del célebre antropólogo, sino -como acertadamente señala Gutiérrez Estévez (2001)- que considere a los mitos como escritos y que sean básicamente textos, cuando sabemos que son versiones orales y, sobre todo, que sus receptores son siempre oyentes y no lectores. Sin embargo, si aceptamos que los mitos -tal como los conocemos- son el producto del etnógrafo, entonces, sí se puede entender una reflexión como la anterior, en la medida que las historias recogidas no pertenecen a la vida social de la gente, sino a la tradición textualista antropológica y su conocimiento concerniente al mundo de los otros, y -quizás- al conjunto resultante del diálogo entre culturas que supone la comprensión.

\section{A modo de Conclusión}

De hecho, los mitos también tienen mucho que informarnos respecto de la cultura andina a quienes no formamos parte de ella, aunque -como recuerda Mannheim (1999)- los andinos nunca dicen nada cuando se les pide que cuenten un mito, porque no los conocen, porque sus historias nacen en contextos de conversación. Ahí viven y tienen, a veces -como dice Zavala-, la misión de transmitir un discurso moral tácito, pues son también una estrategia de transmisión cultural de valores que pasa a otras generaciones para que aprendan las habilidades necesarias para trabajar, tener coraje, abordar el sufrimiento, etc. (Zavala 2010). Constituyen, entonces, una suerte de sistema educativo que busca instruir a sus miembros en la sabiduría de su cultura, una forma de transmitir conocimientos, creencias, etc. Los discursos orales son también, a decir de Vich y Zavala, 
formas de memoria colectiva a través de las cuales los sujetos encuentran fundamentos para constituir su identidad y repensar su presente [...]. Actualizadas en situaciones concretas, algunas performances orales funcionan como rituales que escenifican las experiencias vividas y aspiran a intervenir en las políticas de la memoria (2004:18).

Así, al utilizar las fuentes orales en un proceso que intenta reconstruir las imágenes -históricas o no- de una sociedad carente de escritura como la andina, se hace necesario, como afirma Gary Gossen (1992) para el caso de los Chamula de Chiapas, reconocer en el ritual la existencia de verdaderos textos culturales que constituyen medios de registro y concepción de su experiencia. Adicionalmente, al no poder reconocer en las "narraciones" andinas existentes en las crónicas la presencia de experiencias históricas, resulta importante aprender a leer la oralidad de sus narrativas y sus rituales, así como resulta imprescindible extirpar la idea que los mitos son historias, pues es evidente que no son narraciones, sino que fueron transformadas en ellas tanto por las preguntas planteadas por el interlocutor, cronista o antropólogo como por su posterior registro escrito. Es así como se transformaron en narraciones, y en mitos, conversaciones que, en opinión de Manuel Gutiérrez Estévez (2001, 2003), constituyen verdaderos juegos del lenguaje en los que los participantes van construyendo, juntos, una versión que puede variar considerablemente en los diversos contextos narrativos. Es pues necesario, independientemente de si proceden de una crónica, un documento burocrático virreinal o una conversación contemporánea, despojarlos de su narratividad y entenderlos como juegos del lenguaje que de hecho pueden informar acerca de las concepciones de la gente y que, junto a los rituales, constituyen fuentes capaces de informar a sus sociedades. Solo de esa manera, entendiendo los mitos lejos del alcance de la universalidad, como atribuyera Lévi-Strauss, y de su identificación con los mitos griegos dentro de un mecanismo que los rotula como falsos en la medida que se oponen a los relatos verdaderos asociados, tanto con las Sagradas Escrituras como con la Historia, es que se puede entender su contenido.

En nuestro medio, hay varias maneras de acercarse y percibir a la cultura andina, entendida como aquella que no es compartida por la clase dirigente nacional, la cultura no canónica, que históricamente ha sido básicamente andina ${ }^{2}$. Un primer acercamiento a esta cultura es de "purificación"; es decir, se han seleccionado cuidadosamente los elementos populares que se "pueden" integrar al proyecto nacional de construcción de una identidad a partir de un pasado común. Este proceso, como bien se sabe, empezó hacia los años de la independencia, o quizás antes, con la incorporación del glorioso pasado inca como digno de memoria colectiva. Como es evidente, los admirados incas ya estaban muertos, y sus descendientes andinos no tienen nada que ver con quienes adoptaron esta forma de acercamiento al pasado peruano. El orgullo incaico está evidentemente divorciado del poblador andino. Una segunda forma de acercamiento es con desprecio, considerando lo andino como inferior a lo canónico, lo occidental. Aquí hay muchas variantes; aunque no es este un espacio para analizarlas, sí es oportuno mencionarlas. Dentro de esta apreciación, el castellano será una lengua "superior" al quechua o al aimara, y, por cierto, también al castellano andino, que es considerado una aberración. Evidentemente, no hay ningún criterio científico para esta actitud, que es única y exclusivamente un prejuicio sin fundamento.

En ese sentido, consideramos de suma importancia intentar entender lo que la gente piensa, y buscar una alternativa de comprensión que nos permita resolver, por lo menos teóricamente, la complejidad cultural de nuestro país y desterrar las prácticas excluyentes que la ciencia ha ayudado a fabricar. Es así como debemos entender y leer los textos que escribieron los cronistas, como espacios de comprensión cultural entre estos dos mundos que empezaron a dialogar. Es importante destacar que, desde las tradiciones filosóficas germana y angloamericana, comprender al otro es conocer sus creencias y estados mentales en un proceso en el que no se reconstruye su vida mental, sino más bien se crea un espacio compartido (Quintanilla 2002). Por este camino, es útil el planteamiento de Quintanilla, quien -al retomar el principio de "caridad", propuesto originariamente por Willard van Orman Quine y Donald Davidson- ofrece una reformulación del mismo, a partir de la noción de "simulación". De acuerdo con esta, en un proceso de comprensión del otro, se desarrollaría la capacidad de ponerse en el lugar de este bajo condiciones contrafácticas. Definitivamente, como manifiesta el propio Quintanilla, esta teoría de la 
comprensión puede conducir a alguna forma de etnocentrismo. Sin embargo, también, presentaría la posibilidad de superar la dicotomía entre etnocentrismo y relativismo cultural, en un proceso que permite conocer al otro a partir, evidentemente, de categorías mentales propias, en la medida que se le asume como igual e interpretable (Quintanilla 2002, 2004). Aunque sea inevitable interpretar al otro como semejante, e incluso esta práctica pueda considerarse una suerte de etnocentrismo, resulta también deseable, pues posibilita la interpretación. Esta misma se realiza necesariamente centrada en uno e involucra una comparación entre las categorías mentales propias y las del "otro", y permite desarrollar actitudes morales y compromisos para con los demás. Este "etnocentrismo" deseable e inevitable se opondría, en opinión de Quintanilla, a aquel "etnocentrismo" indeseable que se origina cuando, en el proceso de interpretación, se asume a la propia cultura como axiológica y axiomáticamente superior ${ }^{3}$.

Es precisamente por este camino que debemos comprender la cultura tradicional. En primer lugar, debemos considerarla semejante a la occidental. Solo así se puede entender la multiculturalidad nacional. Por el lado que nos ocupa, que es el de entender la cultura andina tradicional, sabemos que, como manifiesta José Luis Martínez (2010), desde antes de la invasión española existieron temas, motivos, conocimientos colectivos, ya fueran estos míticos o de memoria política o de cualquier índole, que eran transmitidos en distintos soportes, ya fueran estos orales, visuales o dramatizados. Incluso, como demuestra este autor, en ocasiones, un mismo relato o ciclo mítico pudo ser representado en varios de estos soportes por Martínez (2010). Se sabe que, desde hace más de siete mil años -y me refiero a las pinturas rupestres de Lauricocha-, el hombre andino utilizaba la pintura para representar y decir cosas. Por muchos años, diversos soportes sirvieron para esa transmisión; en algunos casos, también, de memoria. Así, los diversos estilos cerámicos andinos, los tejidos, los bailes, y las dramatizaciones han transmitido un mensaje que sospechamos, con ciertas transformaciones, se sigue transmitiendo por medio del arte que se denomina popular. José Luis Martínez lidera, desde hace mucho, un grupo de investigación en Chile que busca las fuentes de estos relatos, sobre todo en los queros, y ha entregado importantes conclusiones ${ }^{4}$. Evidentemente, las fuentes de la cultura popular también deben someterse a la crítica y al contraste, pues nos muestran un ángulo de la realidad, pero es ya tiempo de su revaloración e incorporación al discurso académico. Por el lado de las crónicas, es necesario abandonar la idea de que constituyen repositorios de datos históricos, pero también es necesario releerlas en búsqueda de los mensajes que estos textos nos ofrecen en tanto constituyen verdaderas traducciones culturales de una cultura que a todas luces, quienes escribieron estos textos, quisieron comprender, y, por lo tanto, ante la ausencia de fuentes escritas, nos siguen mostrando información invalorable.

\section{Referencias Citadas}

Gossen, G.H.

1992 Las variaciones del mal en una fiesta Tzotzil. De palabra y obra en el Nuevo Mundo, editado por Miguel León-Portilla y otros, Tomo I, pp. 195-235. Siglo XXI, Madrid, España.

Gutiérrez Estévez, M.

2001 Representaciones míticas y juegos del lenguaje. Indiana 19-20: 89-98.

Gutiérrez Estévez, M.

2003 Representaciones míticas y juegos del lenguaje. Revista Española de Antropología Americana 33: 27-34.

Lévi-Strauss, C.

1968 Antropología estructural. Euduba, Buenos Aires, Argentina. Mannheim, B.

1999 Hacia una mitografía andina. En Tradición oral andina y amazónica. Métodos de análisis e interpretación de textos, compilado por Juan Carlos Godenzzi, pp. 47-79. Centro de Estudios Regionales Andinos "Bartolomé de las Casas", Cuzco, Perú.
Martínez, J.L.

2010 "Mandó pintar dos aves...": relatos orales y representaciones visuales andinas. Chungara. Revista de Antropología Chilena 42 (1): 157-167.

Martínez, J.L.

2011 ¿Cómo recordar? La construcción de las memorias andinas coloniales (siglos XVI y XVII). En Sobre los Incas, editado por Liliana Regalado de Hurtado y Francisco Hernández Astete, pp. 191-217. Pontificia Universidad Católica del Perú / Instituto Riva-Agüero, Lima, Perú.

Molina, C.

1989 Relación de fábulas y mitos de los incas [1574-5]. En Fábulas y mitos de los incas, editado por Henrique Urbano y Pierre Duviols, pp. 47-134. Historia 16, Madrid, España.

Quintanilla Pérez-Wicht, P.

1993 El otro como extensión del yo: respuesta a Antonio Pérez. Arete V (1-2), 167-168. Pontificia Universidad Católica del Perú, Lima, Perú. 
Quintanilla Pérez-Wicht, P.

2002 El lugar de la racionalidad en la comprensión del otro. En Estudios Culturales. Discursos, poderes, pulsiones, editado por Santiago López Maguiña, Gonzalo Portocarrero, Rocío Silva Santisteban y Víctor Vich, pp. 357-381. Red para el Desarrollo de las Ciencias Sociales en el Perú, Lima, Perú.
Vich, V. y V. Zavala.

2004 Oralidad y poder. Herramientas metodológicas. Enciclopedia Latinoamericana de Sociocultura y Comunicación. Grupo Editorial Norma, Bogotá, Colombia. Zavala, V.

2010 La oralidad como performance: un análisis de géneros discursivos andinos desde una perspectiva sociolingüística [2006]. Boletín del Instituto Riva Agüero 33: 129-137.

\section{Notas}

1 Se podría encontrar muchos otros ejemplos de la manera en que los españoles entienden la tradición oral en tanto "indisciplinada" frente a la escritura. Esta situación se sigue encontrando en las escuelas bilingües contemporáneas: "[...] más parecen sueños lo que refieren que historias [...]" (Acosta 1962: 63).
2 Habría que señalar, para el caso peruano, la cultura popular tiene una suerte de doble alteridad frente a la cultura.

3 Para un mayor análisis de este problema, ver Quintanilla (1993, 2002).

4 Ver, por ejemplo, Martínez $(2010,2011)$. 